\title{
Melanoma pathology reporting and staging
}

\author{
Richard A. Scolyer $\mathbb{D}^{1,2,3} \cdot$ Robert V. Rawson ${ }^{1,2,3} \cdot$ Jeffrey E. Gershenwald ${ }^{4}$ Peter M. Ferguson ${ }^{1,2,3} \cdot$ Victor G. Prieto $^{4}$
}

Received: 24 October 2019 / Accepted: 24 October 2019 / Published online: 22 November 2019

(c) The Author(s), under exclusive licence to United States \& Canadian Academy of Pathology 2019

\begin{abstract}
The pathological diagnosis of melanoma can be challenging. The provision of an appropriate biopsy and pertinent history can assist in establishing an accurate diagnosis and reliable estimate of prognosis. In their reports, pathologists should document both the criteria on which the diagnosis was based as well as important prognostic parameters. For melanoma, such prognostic parameters include tumor thickness, ulceration, mitotic rate, lymphovascular invasion, neurotropism, and tumor-infiltrating lymphocytes. Disease staging is important for risk stratifying melanoma patients into prognostic groups and patient management recommendations are often stage based. The 8th edition American Joint Committee on Cancer (AJCC) Melanoma Staging System was implemented in 2018 and several important changes were made. Tumor thickness and ulceration remain the key T category criteria. T1b melanomas were redefined as either ulcerated melanomas $<1.0 \mathrm{~mm}$ thick or nonulcerated melanomas $0.8-1.0 \mathrm{~mm}$ thick. Although mitotic rate was removed as a $\mathrm{T}$ category criterion in the 8 th edition, it remains a very important prognostic factor and should continue to be documented in primary melanoma pathology reports. It was also recommended in the 8th edition that tumor thickness be recorded to the nearest $0.1 \mathrm{~mm}$ (rather than the nearest $0.01 \mathrm{~mm}$ ). In the future, incorporation of additional prognostic parameters beyond those utilized in the current version of the staging system into (web based) prognostic models/clinical tools will likely facilitate more personalized prognostic estimates. Evaluation of molecular markers of prognosis is an active area of current research; however, additional data are needed before it would be appropriate to recommend use of such tests in routine clinical practice.
\end{abstract}

\section{Introduction}

One of the most important challenges clinicians face is to estimate the risk of metastasis and death for any cancer. This is important firstly, because patients want to know what is likely to happen to them and secondly, because management recommendations are principally based upon this risk. In melanoma, these include recommendations related to the definitive management of the primary tumor

Richard A. Scolyer

richard.scolyer@health.nsw.gov.au

1 Melanoma Institute Australia, The University of Sydney, Sydney, NSW, Australia

2 Sydney Medical School, The University of Sydney, Sydney, NSW, Australia

3 Tissue Pathology and Diagnostic Oncology, Royal Prince Alfred Hospital \& NSW Health Pathology, Camperdown, NSW 2050, Australia

4 University of Texas, MD Anderson Cancer Center, Houston, TX 77030, USA site such as the width of excision margins and the role of sentinel lymph node (SLN) biopsy as well as recommendations for the frequency and duration of clinical follow-up [1]. It has recently been demonstrated that targeted and immune therapies, when administered in an adjuvant setting for stage III melanoma, are associated with a 50\% improvement in relapse-free survival [2-4]. It is therefore more important than ever that patients not only receive an accurate diagnosis but also an accurate estimate of prognosis in order to select the correct therapy.

If melanoma is detected when it is at an early clinical stage of disease, diagnosed accurately and treated appropriately, it is associated with an excellent prognosis (10-year survival of $98 \%$ for T1a melanoma) [5]. Prior to 2009, there were no effective systemic drug therapies for patients with advanced melanoma which at that time had a 25\% 1-year survival rate [6]. Underpinned by improved understanding of the molecular basis of melanoma and regulation of immune system [7], new effective targeted and immune therapies have transformed the management of patients with widespread melanoma metastases. Indeed, in 2019, 1-year survival rates of $\sim 75 \%$ have been reported in American Joint Committee on Cancer (AJCC) stage IV 
melanoma patients treated with targeted or immune therapies [8, 9].

\section{What pathologists need from clinicians to accurately diagnose end stage melanoma}

Provision of an appropriate biopsy and pertinent clinical history are keys to the accurate diagnosis and prognostication of melanoma. Unless there are clinical reasons to do otherwise, it is usually recommended that an excision biopsy be performed for diagnosing lesions that are clinically suspected to be melanoma [10]. Partial biopsies, such as shave and particularly punch biopsies, that do not include the entire lesion, have been associated with an increased risk of misdiagnosis $[11,12]$. Pertinent clinical information that assists pathologists when interpreting pigmented lesions includes the age of the patient and site of the lesion. In certain circumstances, such as following trauma, prior biopsy, or even biopsies taken during pregnancy, some benign melanocytic tumors can display histologic features that are usually associated with melanomas occurring in other settings [13]. Therefore, such lesions are at risk at being overdiagnosed as melanoma if the pathologist is not aware of the clinical scenario. The duration for which the lesion has been present and any history of recent change together with the clinical diagnosis or differential diagnosis may also be of assistance to the pathologist when interpreting the biopsy. Despite widespread knowledge of the importance of the provision of pertinent clinical information on pathology request forms, and recommendations in clinical practice guidelines [13], in one recent large study, no useful clinical information whatsoever was provided in $46 \%$ of melanoma pathology request/requisition forms ( $n=1200$, de Menezes and Mar unpublished data). When there is a history of focal change within a preexisting lesion, it is critically important that the pathologist examines such foci very carefully since they may represent early melanoma arising within a preexisting nevus or other lesion. Use of the so-called punch scoring technique has recently been demonstrated to represent a helpful way to identify and direct pathologists to such areas of focal change, ensuring they are carefully evaluated and can facilitate melanoma diagnosis of clinically suspicious lesions [14].

\section{Melanoma pathology report}

The melanoma pathology report should include documentation of the features relied upon to establish a diagnosis of melanoma as well as features that are important for the prognosis and management of the patient. The use of a
Table 1 A synoptic or structured pathology report for primary cutaneous melanoma

\begin{tabular}{|c|c|}
\hline Pathologic feature & Example \\
\hline Site & Right upper leg \\
\hline Diagnosis & $\begin{array}{l}\text { Melanoma, dermal } \\
\text { invasive }\end{array}$ \\
\hline Breslow thickness & $2.3 \mathrm{~mm}$ \\
\hline Ulceration (diameter in $\mathrm{mm}$ ) & Present $(1.1 \mathrm{~mm})$ \\
\hline Dermal mitotic rate $\left(\right.$ per $\left.\mathrm{mm}^{2}\right)$ & 8 \\
\hline Melanoma subtype & $\begin{array}{l}\text { Superficial spreading/ } \\
\text { low CSD [43] }\end{array}$ \\
\hline Vascular or lymphatic invasion & Absent \\
\hline Neurotropism & Absent \\
\hline $\begin{array}{l}\text { Desmoplastic melanoma component (\% of } \\
\text { dermal invasive tumor, if present) }\end{array}$ & Absent \\
\hline \multicolumn{2}{|l|}{ TILs } \\
\hline Distribution & Focal \\
\hline Density & Dense \\
\hline Microsatellites & Absent \\
\hline \multicolumn{2}{|l|}{ Regression: } \\
\hline $\begin{array}{l}\text { Intermediate (angiofibroplasia } \pm \text { TILs), if } \\
\text { present }\end{array}$ & Absent \\
\hline Late (fibrosis and loss of rete ridges) & Absent \\
\hline Predominant cell type & Epithelioid \\
\hline Associated nevus & Nil \\
\hline Solar elastosis & Moderate $(2+)$ \\
\hline \multicolumn{2}{|l|}{ Margins of excision } \\
\hline $\begin{array}{l}\text { Invasive component-nearest } \\
\text { peripheral margin }\end{array}$ & $3.5 \mathrm{~mm}$ \\
\hline $\begin{array}{l}\text { In situ component-nearest } \\
\text { peripheral margin }\end{array}$ & $7.6 \mathrm{~mm}$ \\
\hline Deep margin & $4.1 \mathrm{~mm}$ \\
\hline
\end{tabular}

TILs tumor-infiltrating lymphocytes, CSD cumulative sun damage

synoptic or structured reporting format can facilitate this (Table 1) [15-17]. The prognosis for patients with clinically localized primary melanoma is principally dependent on the tumor thickness, which is measured as described by Breslow [18]. Other important prognostic features for primary melanoma include ulceration [19], mitotic rate [20], lymphovascular invasion, tumor-infiltrating lymphocytes (TILs) [21], melanoma subtype (e.g. desmoplastic melanoma is less frequently associated with nodal metastasis and has a more favorable prognosis [22, 23]), as well as patient characteristics such as age, gender, and anatomical site of the tumor (young patient age, female gender and melanoma arising on the extremities are each associated with a more favorable prognosis).

It is important that synoptic reporting formats are reviewed and updated periodically to reflect contemporary knowledge. Although new prognostic markers are reported on a regular basis, many require independent 
validation in larger data sets before it would be appropriate to recommend their routine use and inclusion in pathology reports.

\section{8th edition AJCC melanoma staging system}

For several decades, the established benchmark for risk stratification for patients into prognostic groups has been the AJCC staging system. This is updated periodically and the most recent (8th) edition became operational in 2018 [24]. The staging system is also important for eligibility, stratification, and analysis of clinical trials. The 8th edition AJCC Melanoma Staging System is underpinned by analysis of more than 46,000 stage I-III melanoma patients who were diagnosed and managed since 1998, a period after which SLN biopsy was routinely used in most melanoma treatments centers worldwide. In November 2015, the International Melanoma Pathology Study Group (IMPSG) met at the University of California, San Francisco, and considered, discussed, debated, and voted upon various pathology staging issues. The consensus recommendations from the IMPSG were subsequently taken to the AJCC melanoma expert panel and were incorporated into the 8th edition Staging System.

Similar to the staging of other cancers, melanoma staging is divided into four stages with stages I and II for clinically localized primary melanoma, stage III for patients with locoregional metastases, and stage IV for those patients with distant metastases.

\section{AJCC T category criteria}

The $\mathrm{T}$ category is divided into T1-T4 based on the tumor thickness. Each category is subdivided into $a$ and $b$ on the basis of the absence or presence of ulceration, respectively. In addition, nonulcerated tumors $0.8-1 \mathrm{~mm}$ thick are categorized at $\mathrm{T} 1 \mathrm{~b}$ tumors (Table 2).

When reporting tumor thickness, it is recommended in the 8 th edition that the thickness be recorded to the nearest $0.1 \mathrm{~mm}$. The principal reason for this is because it is generally impractical and imprecise to measure to the nearest 100th of a millimeter for tumors $>1 \mathrm{~mm}$ thick. Whilst for thinner tumors they may be measured to the nearest 100th of a millimeter, it is recommended that they be rounded up or down to the nearest $0.1 \mathrm{~mm}$ for recording in the pathology report to be used in the AJCC scheme. The 8th edition provides clear guidance for the application of rounding up and down. For example, any melanoma measuring $0.75-0.84 \mathrm{~mm}$ in thickness would be rounded to $0.8 \mathrm{~mm}$ and recorded as a T1b melanoma. Similarly, a melanoma measuring $1.04 \mathrm{~mm}$ thick would be recorded as $1.0 \mathrm{~mm}$ in the pathology report and designated as T1b for staging.

Data from a number of large independent data sets supported the selection of $0.8 \mathrm{~mm}$ as an appropriate
Table 2 Definition of primary tumor $(\mathrm{T})$

\begin{tabular}{lll}
\hline T Category & Thickness & Ulceration status \\
\hline $\begin{array}{c}\text { TX: primary tumor thickness cannot be assessed (e.g., } \\
\text { fragmented biopsy) }\end{array}$ & Not applicable & Not applicable \\
$\begin{array}{c}\text { T0: no evidence of primary tumor (e.g., unknown primary } \\
\text { or completely regressed primary melanoma) }\end{array}$ & Not applicable & Not applicable \\
Tis (melanoma in situ) & Not applicable & Not applicable \\
T1 & $\leq 1.0 \mathrm{~mm}$ & Unknown or unspecified \\
T1a & $<0.8 \mathrm{~mm}$ & Without ulceration \\
T1b & $<0.8 \mathrm{~mm}$ & With ulceration \\
& $0.8-1.0 \mathrm{~mm}$ & With or without ulceration \\
T2 & $>1.0-2.0 \mathrm{~mm}$ & Unknown or unspecified \\
T2a & $>1.0-2.0 \mathrm{~mm}$ & Without ulceration \\
T2b & $>1.0-2.0 \mathrm{~mm}$ & With ulceration \\
T3 & $>2.0-4.0 \mathrm{~mm}$ & Unknown or unspecified \\
T3a & $>2.0-4.0 \mathrm{~mm}$ & Without ulceration \\
T3b & $>2.0-4.0 \mathrm{~mm}$ & With ulceration \\
T4 & $>4.0 \mathrm{~mm}$ & Unknown or unspecified \\
T4a & $>4.0 \mathrm{~mm}$ & Without ulceration \\
T4b & $>4.0 \mathrm{~mm}$ & With ulceration \\
\hline A & & \\
\hline
\end{tabular}

Adapted with permission of the American Joint Committee on Cancer (AJCC), Chicago, Illinois. The original and primary source for this information is the AJCC Cancer Staging Manual, 8th edition (2017) published by Springer International Publishing

Modified from ref. [24] 


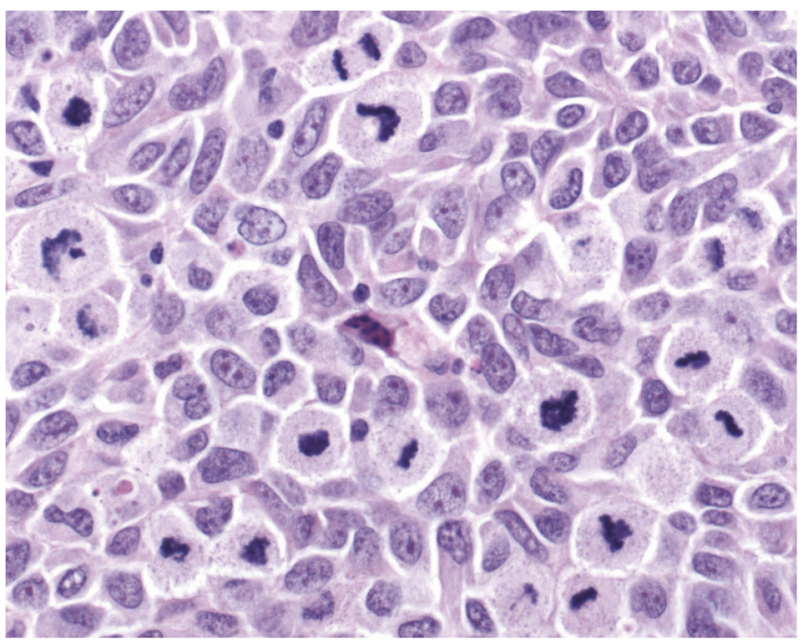

Fig. 1 Melanoma with multiple mitotic figures. High mitotic rate is an independent predictor of adverse outcome in melanoma patients

cut-off point for subcategorizing nonulcerated T1 melanomas [25-27].

Mitotic rate was removed as a T1 subcategory criterion in the 8th edition. This represents a change from the 7th edition. Nevertheless, mitotic rate represents a very strong independent predictor of outcome across its dynamic range in clinically localized primary melanoma patients and should be recorded in all melanoma pathology reports (Fig. 1). There were a number of reasons for removing mitotic rate as a staging parameter in the 8th edition. Importantly, using an international database that informed the 8th edition, in $\mathrm{T} 1$ analyses that included tumor thickness stratified by $<0.8 \mathrm{~mm}$ versus $\geq 0.8 \mathrm{~mm}-1.0 \mathrm{~mm}$, presence or absence of ulceration, and mitotic rate as a dichotomous variable, the latter factor, mitotic rate, was no longer significant [5]. Concern has also been expressed that pathologists may be looking more carefully for a single mitotic figure following its introduction as a staging parameter in the 7th edition, which may have resulted in fewer melanomas being identified with zero mitotic figures than were identified in the data sets upon which its prognostic significance was originally assessed. Furthermore, it was on occasion erroneously stated that mitotic rate was only prognostically significant as a dichotomous variable (less than or greater than or equal to $1 / \mathrm{mm}^{2}$ ) when in fact it is strongly prognostic across its full dynamic range [5]. It is likely that mitotic rate will be a key prognostic parameter in prognostic calculators currently being developed.

Mitotic rate should be assessed using the "hot spot" method in all T1-T4 primary melanomas [28]. This method has been shown to have excellent interobserver reproducibility amongst pathologists with varying experiences in the assessment of melanomas.

In the 8th edition, $\mathrm{T} 0$ designates patients in whom no evidence of a primary tumor is identified, e.g., a patient who presents with nodal metastasis and no known primary melanoma. Tis is used to designate melanoma in situ. TX is used when tumor thickness cannot be determined. The latter might occur because of perpendicular sectioning in a curettage-type or fragmented specimen (see also next section).

\section{Challenges with measuring tumor thickness}

Pathologists may be faced with a number of challenges when measuring tumor thickness. Occasionally, it can be difficult to determine whether atypical nevoid cells within the dermis represent maturing, benign-appearing melanoma cells or part of a preexisting nevus. In such instances, it may be problematic to determine the deepest dermal cell to measure the tumor thickness. Comparison of the cytological features to both the clearly invasive component as well as any associated benign nevus can assist. Nevertheless, this usually requires careful and reasoned judgment.

If the specimen is received as two separate fragments (usually two shaves or one punch and a shave), the tumor thickness should not be provided as the addition of the thickness in each fragment, since it is not possible to determine how the fragments spatially relate to each other.

When there is deep periadnexal extension of melanoma as a "tongue" of tumor that extends much more deeply than the main, more superficial part of the dermal invasive melanoma, it is not recommended that such extension be included in the measurement of tumor thickness, unless this represents the only focus on invasion. Recently published data by Dodds et al. [29] provided evidence based on outcome data that periadnexal extension should not be included in tumor thickness measurements. When periadnexal melanoma represents the only focus of invasion, tumor thickness should be measured from the middle of the adnexal structure from where it has likely risen.

Microsatellites or foci of neurotropism or lymphovascular invasion should not be included in the measurement of the Breslow thickness.

\section{Ulceration}

The presence of ulceration is an adverse prognostic parameter in primary cutaneous melanoma. It is important to distinguish true ulceration from separation of the epidermis from the underlying tumor as a result of sectioning or other artefactual disruption. The presence of a tissue reaction to loss of epidermis with fibrin and acute inflammation are important histopathologic hallmarks of true ulceration (Fig. 2). Not only is the presence or absence of ulceration important prognostically but also the width of ulceration is 

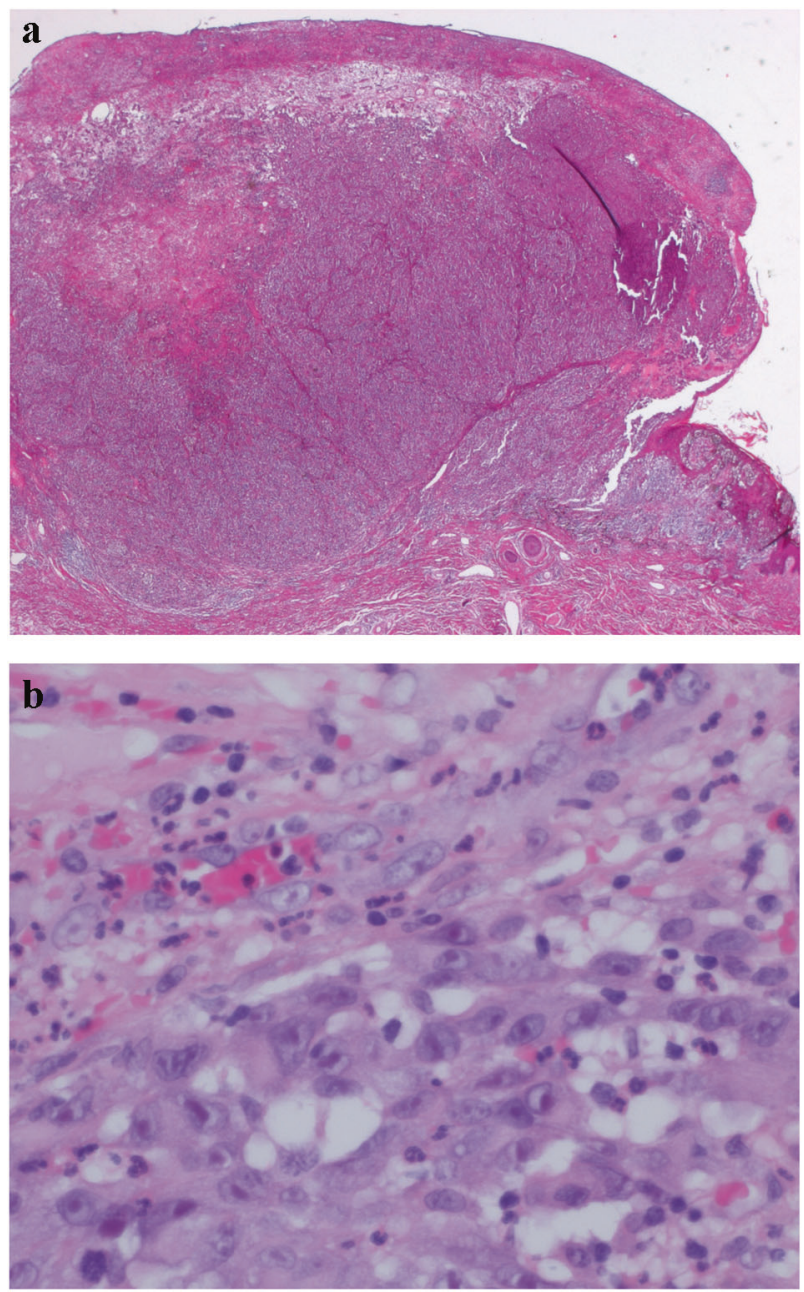

Fig. 2 a, b Ulcerated nodular melanoma. A fibrinopurulent exudate is present on the surface

strongly associated with outcome. Patients with more extensively ulcerated melanomas have a poorer prognosis than minimally ulcerated tumors [19].

\section{Melanoma subtype}

Desmoplastic melanoma is an uncommon subtype of melanoma (1-4\%) characterized by the presence of spindled melanoma cells within fibrosclerotic stroma (Fig. 3a). It often has a subtle appearance both clinical and pathological and might not be diagnosed until it is at an advanced clinical stage. Compared with other melanoma subtypes, it is associated with less frequent nodal metastasis, better overall survival and better response rates to immune therapy [22, $23,30]$. This is particularly true for the "pure" subtype of desmoplastic melanoma, where the desmoplastic component (malignant spindle cells separated by fibroblastic stroma often with accompanying myxoid change and lymphoid aggregates) accounts for $>90 \%$ of the invasive
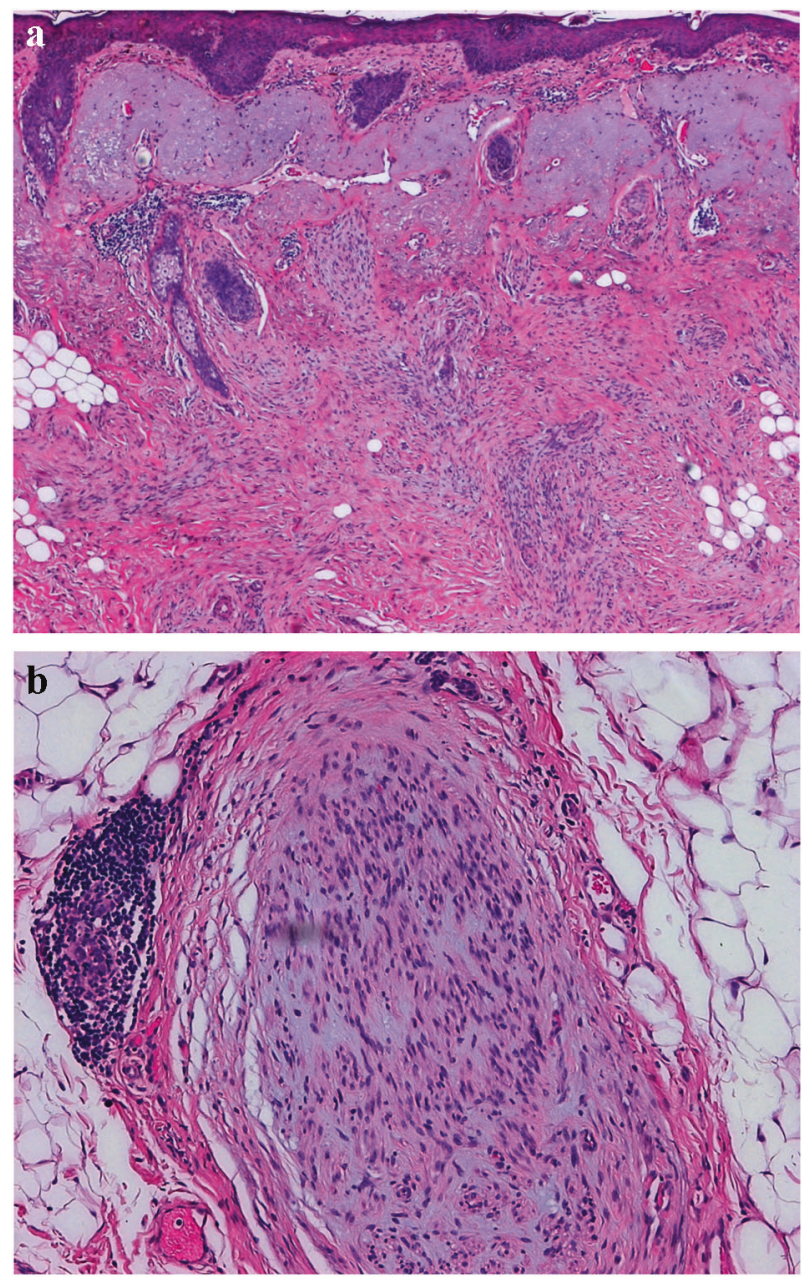

Fig. 3 a Desmoplastic melanoma of pure subtype involving severely sun damaged skin. b A focus of neurotropism (intraneural invasion) is present

melanoma. It typically occurs in the head and neck region in severely sun-damaged skin of elderly patients. It may be associated with a lentigo maligna in the overlying epidermis or an atypical epidermal melanocytic proliferation. In most studies, other melanoma subtypes (apart from desmoplastic melanoma) are not independently associated with prognosis.

\section{Neurotropism}

The two major forms of neurotropism are perineural invasion and intraneural invasion (Fig. 3b). Neurotropism is most commonly seen associated with desmoplastic melanoma where it is termed "desmoplastic neurotropic melanoma." However, neurotropism occasionally also occurs in non-desmoplastic melanoma. Neurotropic melanoma may extend well beyond on the edge of the primary tumor. For this reason, it is associated with an increased risk of local 
recurrence [31]. At some, but not all, melanoma treatment centers, the presence of neurotropism instigates the application of postoperative radiotherapy to reduce the risk of local occurrence [31].

\section{Tumor-infiltrating lymphocytes}

The presence of TILs signifies that the host immune system recognizes and reacts to the tumor. As such, it is a favorable prognostic parameter in primary melanoma. Various grading schemes have been described for the quantification of TILs [32] in melanoma. In general, the more TILs that are present, the better the prognosis is for the patient [21].

\section{Regression}

As is commonly observed clinically in primary melanomas, the immune system can react against a primary melanoma and result in loss of part or all of the tumor. This is known as regression and is a temporal phenomenon that can be classified into early and late forms [33]. Early regression is characterized by immature fibrous tissue and increased vascularity, usually accompanied by a chronic inflammatory cell infiltrate. Late regression is characterized by the presence of mature dermal fibrosis usually with accompanying loss of rete ridges in the overlying epidermis. In some studies, regression has been an adverse prognostic parameter, whilst in others it has been a favorable prognostic parameter [34, 35].

\section{Lymphovascular invasion}

The presence of tumor cells within lymphatics (or blood vessels) at or near the primary melanoma site is an adverse prognostic parameter in melanoma. The use of Immunohistochemical staining for lymphatic and/or vascular markers (such as D2-40 and CD31) accompanied by markers of melanoma cells can be useful for identifying and highlighting lymphovascular invasion (Fig. 4).

\section{Microsatellites}

In the 8th edition, the definition of microsatellites was revised. It is defined as a microscopic metastasis adjacent or deep to a primary tumor site identified on pathological examination. It must be discontinuous from the primary and separate by normal stroma, without fibrosis or inflammation (Fig. 5). The previous minimum size and distance from the primary tumor that formed part of the 7th edition definition are not applicable in the 8th edition. It is recommended that

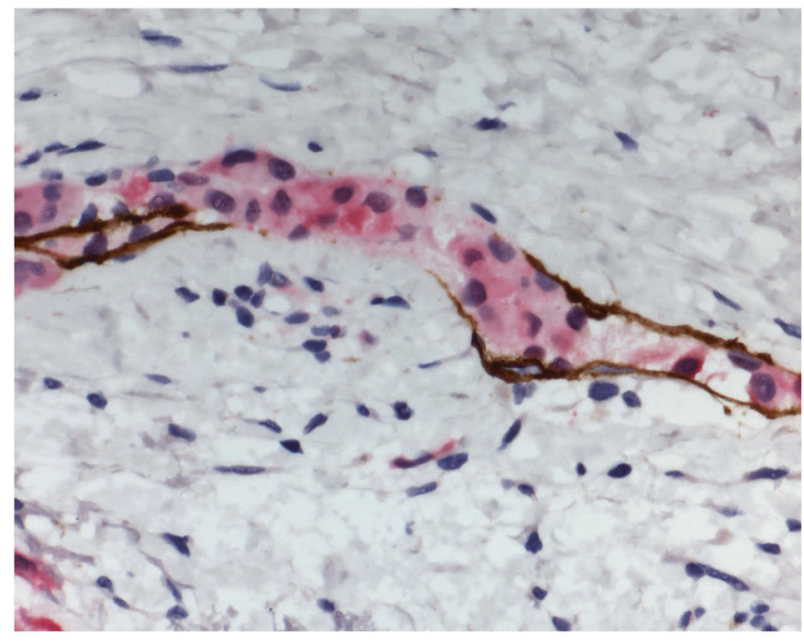

Fig. 4 Lymphatic invasion by melanoma. The melanoma cells have been stained positively with MelanA/MART1 (red chromogen) whilst the lymphatic endothelium is stained with the lymphatic marker D2-40 (brown chromogen)

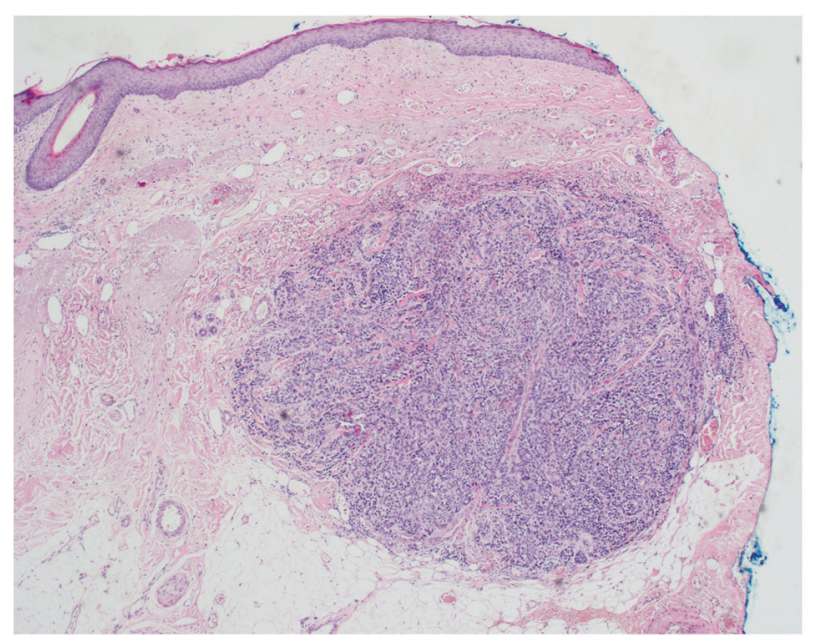

Fig. 5 Microsatellite metastasis identified in a primary melanoma wide excision specimen

when considering a diagnosis of the presence of microsatellites, it is often prudent to examine additional levels of the block of tissue to ensure that the microsatellite is indeed discontinuous from the primary tumor.

\section{AJCC N category}

There are three criteria that define the $\mathrm{N}$ category in the 8 th edition:

(1) the presence of clinically occult regional lymph node metastases identified by sentinel lymph node (SLN) biopsy; 
Table 3 Definition of regional lymph node (N)

\begin{tabular}{|c|c|c|}
\hline \multirow[b]{2}{*}{ N Category } & \multicolumn{2}{|l|}{ Extent of regional lymph node and/or lymphatic metastasis } \\
\hline & Number of tumor-involved regional lymph node & $\begin{array}{l}\text { Presence of in-transit, satellite, } \\
\text { and/or microsatellite metastases }\end{array}$ \\
\hline NX & $\begin{array}{l}\text { Regional nodes not assessed (e.g., SLN biopsy not performed, regional nodes } \\
\text { previously removed for another reason) } \\
\text { Exception: pathological } \mathrm{N} \text { category is not required for } \mathrm{T} 1 \text { melanomas, use } \mathrm{cN} \text {, if } \\
\text { regional lymph nodes not assessed for patient with } \mathrm{T} 1 \text { melanoma }\end{array}$ & No \\
\hline No & No regional metastases detected & No \\
\hline N1 & $\begin{array}{l}\text { One tumor-involved node or any number of in-transit, satellite, and/or microsatellite } \\
\text { metastases with no tumor-involved nodes }\end{array}$ & \\
\hline N1a & One clinically occult (i.e., detected by SLN biopsy) & No \\
\hline N1b & One clinically detected & No \\
\hline N1c & No regional lymph node disease & Yes \\
\hline $\mathrm{N} 2$ & $\begin{array}{l}\text { Two or three tumor-involved nodes or any number of in-transit, satellite, and/or } \\
\text { microsatellite metastases with one tumor-involved node }\end{array}$ & \\
\hline $\mathrm{N} 2 \mathrm{a}$ & Two or three clinically occult (i.e., detected by SLN biopsy) & No \\
\hline $\mathrm{N} 2 \mathrm{~b}$ & Two or three, at least one of which was clinically detected & No \\
\hline $\mathrm{N} 2 \mathrm{c}$ & One clinically occult or clinically detected & Yes \\
\hline $\mathrm{N} 3$ & $\begin{array}{l}\text { Four or more tumor-involved nodes or any number of in-transit, satellite, and/or } \\
\text { microsatellite metastases with two or more tumor-involved nodes, or any number of } \\
\text { matted nodes without or with in-transit, satellite, and/or microsatellite metastases }\end{array}$ & \\
\hline N3a & Four or more clinically occult (i.e., detected by SLN biopsy) & No \\
\hline $\mathrm{N} 3 \mathrm{~b}$ & $\begin{array}{l}\text { Four or more, at least one of which was clinically detected, or presence of any number } \\
\text { of matted nodes }\end{array}$ & No \\
\hline $\mathrm{N} 3 \mathrm{c}$ & $\begin{array}{l}\text { Two or more clinically occult or clinically detected and/or presence of any number of } \\
\text { matted nodes }\end{array}$ & Yes \\
\hline
\end{tabular}

Adapted with permission of the American Joint Committee on Cancer (AJCC), Chicago, Illinois. The original and primary source for this information is the AJCC Cancer Staging Manual, 8th edition (2017) published by Springer International Publishing

Modified from ref. [24]

(2) clinically detected regional lymph nodes (detected either via by physical examination or on radiological imaging); and

(3) the presence of in-transit, satellites, or microsatellite metastases.

The various $\mathrm{N}$ categories are presented in Table 3 .

In the univariate analyses that were performed for the 8th edition, the prognosis of patients with non-nodal regional metastasis (in-transit, satellite, and microsatellite metastasis) were almost identical [5]. For this reason, these three subcategories were grouped together for staging purposes in the 8th edition. In patients with stage III melanoma, the number of locoregional metastases as well as the tumor burden strongly correlates with outcome, i.e., the various $\mathrm{N}$ subcategories correlate with survival. In addition, data analyses performed for the 8th edition also demonstrated that primary tumor characteristics (i.e., the $\mathrm{T}$ subcategory) were also strongly associated with outcome even in patients who had locoregional disease [5]. It is for this reason that both the $\mathrm{T}$ and $\mathrm{N}$ categories were combined to define the stage III groupings in the 8th edition (Table 4). Ten year melanoma specific survival ranges from $88 \%$ for stage IIIA to $24 \%$ for stage IIID melanoma [5].

\section{SLN biopsy}

In the 8th edition staging system, SLN biopsy is required for pathological staging of all patients whose primary melanomas is greater than $1 \mathrm{~mm}$ thick. Many clinical practice guidelines also recommend SLN biopsy be considered in patients with tumors $0.8-1 \mathrm{~mm}$ thickness when other high-risk features are present such as the presence of ulceration, a high mitotic rate, young patient age $(<40)$, or lymphovascular invasion. SLN tumor harboring status represented the strongest predictor of outcome in patients with clinically localized primary melanoma. Furthermore, it may also be helpful in identifying some patients who may benefit from adjuvant systemic therapy.

The SLN tumor burden predicts both the risk of nonSLN metastasis within the regional node field as well as survival in patients with sentinel node metastasis [35-38]. Various surrogates for quantifying SLN tumor burden have 
Table 4 Melanoma stage III subgroups

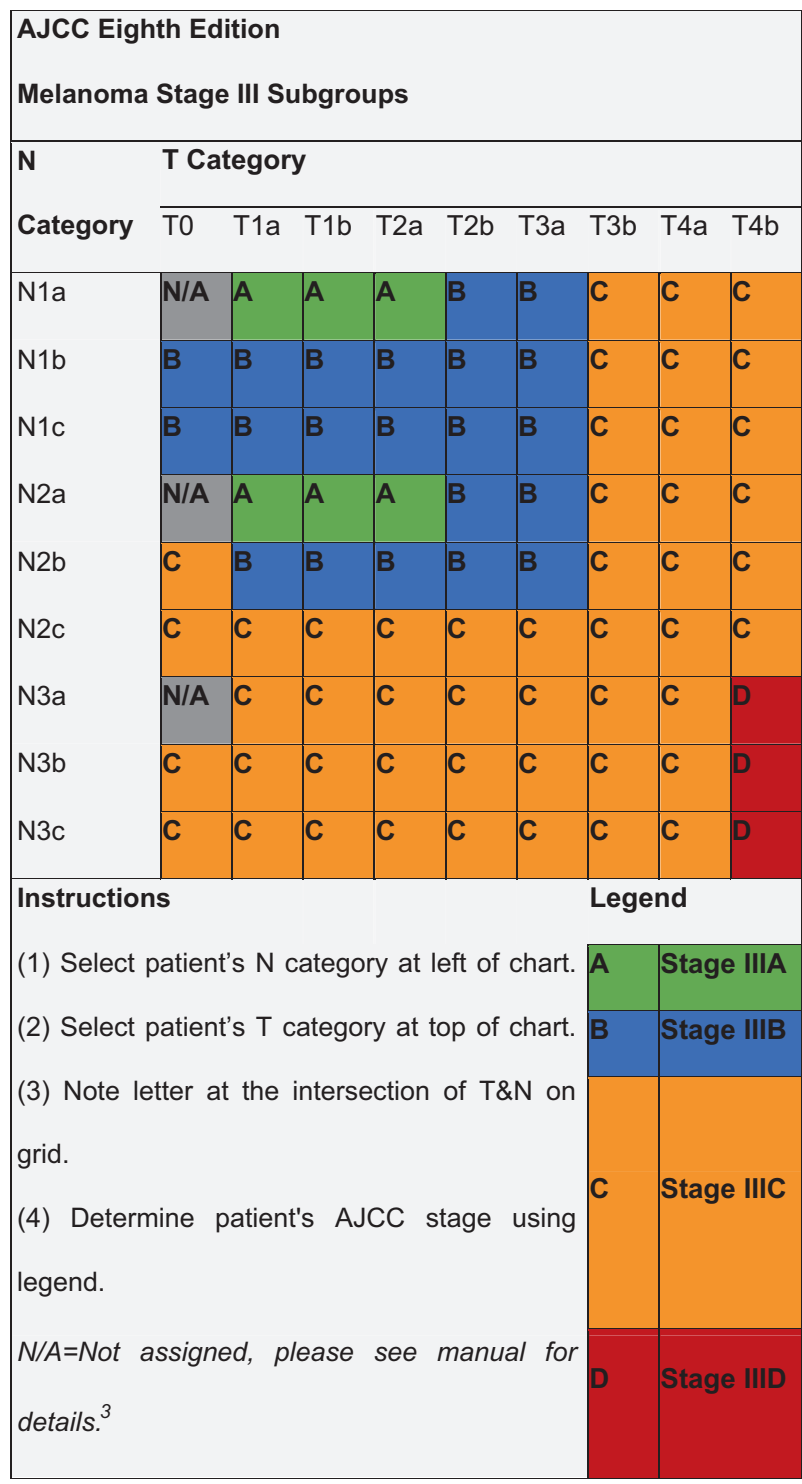

Original source: ref. [5]

been proposed, and in general, all correlate with disease outcomes. The IMPSG and the AJCC melanoma expert panel both recommend that, at a minimum, the largest dimension of the largest metastasis should be recorded in the pathology report. Other parameters that may also be useful for prognosis include the location of the metastases (subcapsular, intraparenchymal, or both), the tumor penetrative depth (centripetal thickness), and the percentage cross-sectional area of the lymph node involved by tumor. The presence of extranodal metastasis, although uncommon in SLNs, is also an adverse prognostic parameter; thus its presence or absence should be recorded in pathology reports of all regional lymph node specimens derived from melanoma cases [39].

\section{AJCC M category}

Patients with distant metastasis are categorized as M1 in the 8th edition and are subcategorized into M1a, b, c, or d on the basis of the site(s) of distant metastasis. Suffixes are added for the $\mathrm{M}$ category for elevated (1) or non-elevated (0) serum lactate dehydrogenase (LDH) levels (Table 5).

\section{AJCC staging rules}

In the 8th edition, clinical staging is defined as being based upon assessment of the initial primary tumor biopsy as well as clinical examination of regional lymph nodes. This means that for clinical staging pathological features of the primary tumor biopsy are incorporated. For pathological staging, pathological features of the definitive treatment of the primary tumor site is utilized (both the primary tumor biopsy and wide excision specimens). Pathological staging should be based on the worst features of either the primary tumor biopsy or wide excision specimen. For example, if an ulcerated T2 melanoma is identified on initial biopsy, it should be designated as cT2b. However, even if there is no ulceration present in the subsequent excision specimen, the associated primary melanoma should still be designated as pT2b. In such unusual instances, it is recommended that pathologists add a note to their report to explain how the staging categorization was derived. It is also specified in the staging system that tumor thickness measured on an initial biopsy and subsequent incision should not be added together to derive the tumor thickness. Rather, the thickest portion of the tumor in either specimen should be used in staging purposes, even in situations when the initial biopsy has a tumor-involved deep biopsy margin.

\section{Limitations of staging}

By necessity, the AJCC staging system can only take into account a limited number of prognostic parameters. Nevertheless, many additional well-established prognostic factors are not incorporated into the staging system. Incorporation of additional prognostic parameters into computerized prognostic algorithms is likely to provide more individualized and accurate prognostic estimates [40].

Prognostic estimates associated with the various AJCC staging categories are defined at the time of initial diagnosis and do not consider changes (improvements) in prognosis that may occur with survival over time in the absence of disease recurrence. The latter is known as a conditional survival estimate. For example, in one study, a patient with AJCC 8th edition stage IIID disease had a 5-year survival of 
Table 5 Definition of distant metastasis (M)

\begin{tabular}{|c|c|c|}
\hline \multirow[b]{2}{*}{ M Category } & \multicolumn{2}{|l|}{$\mathrm{M}$ criteria } \\
\hline & Anatomic site & LDH level \\
\hline M0 & No evidence of distant metastasis & Not applicable \\
\hline M1 & Evidence of distant metastasis & See below \\
\hline M1a & $\begin{array}{l}\text { Distant metastasis to skin, soft } \\
\text { tissue including muscle, and/or }\end{array}$ & $\begin{array}{l}\text { Not recorded or } \\
\text { unspecified }\end{array}$ \\
\hline $\mathrm{M} 1 \mathrm{a}(0)$ & nonregional lymph node & Not elevated \\
\hline M1a(1) & & Elevated \\
\hline M1b & $\begin{array}{l}\text { Distant metastasis to lung with or } \\
\text { without M1a sites of disease }\end{array}$ & $\begin{array}{l}\text { Not recorded or } \\
\text { unspecified }\end{array}$ \\
\hline $\operatorname{M1b}(0)$ & & Not elevated \\
\hline M1b(1) & & Elevated \\
\hline M1c & $\begin{array}{l}\text { Distant metastasis to non-CNS } \\
\text { visceral sites with or without M1a } \\
\text { or M1b sites of disease }\end{array}$ & $\begin{array}{l}\text { Not recorded or } \\
\text { unspecified }\end{array}$ \\
\hline $\mathrm{M} 1 \mathrm{c}(0)$ & & Not elevated \\
\hline $\mathrm{M} 1 \mathrm{c}(1)$ & & Elevated \\
\hline M1d & $\begin{array}{l}\text { Distant metastasis to CNS with or } \\
\text { without M1a, M1b, or M1c sites of }\end{array}$ & $\begin{array}{l}\text { Not recorded or } \\
\text { unspecified }\end{array}$ \\
\hline $\operatorname{M1d}(0)$ & disease & Normal \\
\hline M1d(1) & & Elevated \\
\hline
\end{tabular}

Suffixes for M category: (0) LDH not elevated, (1) LDH elevated. No suffix is used if LDH is not recorded or is unspecified

Used with permission of the American Joint Committee on Cancer (AJCC), Chicago, Illinois. The original and primary source for this information is the AJCC Cancer Staging Manual, 8th edition (2017) published by Springer International Publishing ref. [24]

$10 \%$, however, if the patient was still alive in 5 years, they had a $50 \%$ chance of being alive 5 years later (i.e., 10 years after initial diagnosis) [41].

\section{Molecular markers of prognosis}

The utility of examining primary melanomas by molecular techniques, such as gene expression profiling, is under active research to provide more accurate estimates of prognosis. In the future, it is likely that it will be possible to integrate such data into prognostic estimates. Nevertheless, at the present time, additional data are needed before it becomes appropriate to recommend their routine use in clinical practice [42].

\section{Conclusions}

When assessing primary cutaneous melanomas, pathologists should provide a report with sufficient information to facilitate both accurate staging to occur and a reliable estimate of prognosis to be made. This is necessary to establish an evidence-based management plan and is facilitated by employing a structured pathology report. More accurate personalized predication of prognosis is likely to be possible in the future utilizing web-based or other computerized tools, the integration of additional prognostic factors and complex molecular data as well as molecular predictive and diagnostic biomarkers.

\section{Compliance with ethical standards}

Conflict of interest RAS reports receiving fees for professional services from Merck Sharp \& Dohme, GlaxoSmithKline Australia, Bristol-Myers Squibb, Dermpedia, Novartis Pharmaceuticals Australia Pty Ltd, Myriad, NeraCare GmbH, and Amgen. The other authors declare that they have no conflict of interest.

Publisher's note Springer Nature remains neutral with regard to jurisdictional claims in published maps and institutional affiliations.

\section{References}

1. Thompson JF, Scolyer RA, Kefford RF. Cutaneous melanoma. Lancet. 2005;365:687-701.

2. Eggermont AMM, Blank CU, Mandala M, Long GV, Atkinson V, Dalle $S$, et al. Adjuvant pembrolizumab versus placebo in resected stage III melanoma. N Engl J Med. 2018;378:1789-801.

3. Weber J, Mandala M, Del Vecchio M, Gogas HJ, Arance AM, Cowey CL, et al. Adjuvant nivolumab versus ipilimumab in resected stage III or IV melanoma. N Engl J Med. 2017;377:1824-35.

4. Long GV, Hauschild A, Santinami M, Atkinson V, Mandala M, Chiarion-Sileni V, et al. Adjuvant dabrafenib plus trametinib in stage III BRAF-mutated melanoma. N Engl J Med. 2017;377: 1813-23.

5. Gershenwald JE, Scolyer RA, Hess KR, Sondak VK, Long GV, Ross MI, et al. Melanoma staging: evidence-based changes in the American Joint Committee on Cancer eighth edition cancer staging manual. CA Cancer J Clin. 2017;67:472-92.

6. Balch CM, Buzaid AC, Soong SJ, Atkins MB, Cascinelli N, Coit DG, et al. Final version of the American Joint Committee on Cancer staging system for cutaneous melanoma. J Clin Oncol. 2001;19:3635-48.

7. Griewank KG, Scolyer RA, Thompson JF, Flaherty KT, Schadendorf D, Murali R. Genetic alterations and personalized medicine in melanoma: progress and future prospects. J Natl Cancer Inst. 2014;106:djt435.

8. Wolchok JD, Chiarion-Sileni V, Gonzalez R, Rutkowski P, Grob JJ, Cowey CL, et al. Overall survival with combined nivolumab and ipilimumab in advanced melanoma. N Engl J Med. 2017;377: $1345-56$

9. Robert C, Karaszewska B, Schachter J, Rutkowski P, Mackiewicz A, Stroiakovski D, et al. Improved overall survival in melanoma with combined dabrafenib and trametinib. N Engl J Med. 2015; 372:30-9.

10. Rtshiladze MA, Stretch JR, Scolyer RA, Guitera P. Diagnosing melanoma: the method matters. Med J Aust. 2019;211:209-10.

11. Ng JC, Swain S, Dowling JP, Wolfe R, Simpson P, Kelly JW. The impact of partial biopsy on histopathologic diagnosis of cutaneous melanoma: experience of an Australian tertiary referral service. Arch Dermatol. 2010;146:234-9.

12. Scolyer RA, Thompson JF, McCarthy SW, Strutton GM, Elder DE. Incomplete biopsy of melanocytic lesions can impair the accuracy of pathological diagnosis. Australas J Dermatol. 2006;47:71-3. author reply $4-5$ 
13. Scolyer RA, Soyer HP, Kelly JW, James C, McLean CA, Coventry $\mathrm{BJ}$, et al. Improving diagnostic accuracy for suspicious melanocytic skin lesions: new Australian melanoma clinical practice guidelines stress the importance of clinician/pathologist communication. Aust J Gen Pr. 2019;48:357-62.

14. Grogan J, Cooper CL, Dodds TJ, Guitera P, Menzies SW, Scolyer RA. Punch 'scoring': a technique that facilitates melanoma diagnosis of clinically suspicious pigmented lesions. Histopathology. 2018;72:294-304.

15. Haydu LE, Holt PE, Karim RZ, Madronio CM, Thompson JF, Armstrong BK, et al. Quality of histopathological reporting on melanoma and influence of use of a synoptic template. Histopathology. 2010;56:768-74.

16. Scolyer RA, Judge MJ, Evans A, Frishberg DP, Prieto VG, Thompson JF, et al. Data set for pathology reporting of cutaneous invasive melanoma: recommendations from the international collaboration on cancer reporting (ICCR). Am J Surg Pathol. 2013;37:1797-814.

17. Karim RZ, van den Berg KS, Colman MH, McCarthy SW, Thompson JF, Scolyer RA. The advantage of using a synoptic pathology report format for cutaneous melanoma. Histopathology. 2008;52:130-8.

18. Breslow A. Thickness, cross-sectional areas and depth of invasion in the prognosis of cutaneous melanoma. Ann Surg. 1970;172:902-8.

19. In 't Hout FE, Haydu LE, Murali R, Bonenkamp JJ, Thompson JF, Scolyer RA. Prognostic importance of the extent of ulceration in patients with clinically localized cutaneous melanoma. Ann Surg. 2012;255:1165-70.

20. Azzola MF, Shaw HM, Thompson JF, Soong SJ, Scolyer RA, Watson GF, et al. Tumor mitotic rate is a more powerful prognostic indicator than ulceration in patients with primary cutaneous melanoma: an analysis of 3661 patients from a single center. Cancer. 2003;97:1488-98.

21. Azimi F, Scolyer RA, Rumcheva P, Moncrieff M, Murali R, McCarthy SW, et al. Tumor-infiltrating lymphocyte grade is an independent predictor of sentinel lymph node status and survival in patients with cutaneous melanoma. J Clin Oncol. 2012;30:2678-83.

22. Murali R, Shaw HM, Lai K, McCarthy SW, Quinn MJ, Stretch JR, et al. Prognostic factors in cutaneous desmoplastic melanoma: a study of 252 patients. Cancer. 2010;116:4130-8.

23. Busam KJ, Mujumdar U, Hummer AJ, Nobrega J, Hawkins WG, Coit DG, et al. Cutaneous desmoplastic melanoma: reappraisal of morphologic heterogeneity and prognostic factors. Am J Surg Pathol. 2004;28:1518-25.

24. Gershenwald JE, Scolyer RA, Hess KR, Sondak VK, Long GV, Ross MI, et al. In: Amin MB, Edge SB, Greene FL, Carducci MA, Compton CA, editors. AJCC cancer staging manual. 8th ed. Springer International Publishing: New York; 2017. p. 563-85.

25. Cintolo JA, Gimotty P, Blair A, Guerry D, Elder DE, Hammond $\mathrm{R}$, et al. Local immune response predicts survival in patients with thick (t4) melanomas. Ann Surg Oncol. 2013;20:3610-7.

26. Gimotty PA, Elder DE, Fraker DL, Botbyl J, Sellers K, Elenitsas $\mathrm{R}$, et al. Identification of high-risk patients among those diagnosed with thin cutaneous melanomas. J Clin Oncol. 2007;25:1129-34.

27. Green AC, Baade P, Coory M, Aitken JF, Smithers M. Population-based 20-year survival among people diagnosed with thin melanomas in Queensland, Australia. J Clin Oncol. 2012;30: $1462-7$
28. Scolyer RA, Shaw HM, Thompson JF, Li LX, Colman MH, Lo $\mathrm{SK}$, et al. Interobserver reproducibility of histopathologic prognostic variables in primary cutaneous melanomas. Am J Surg Pathol. 2003;27:1571-6.

29. Dodds TJ, Lo S, Jackett L, Nieweg O, Thompson JF, Scolyer RA. Prognostic significance of periadnexal extension in cutaneous melanoma and its implications for pathologic reporting and staging. Am J Surg Pathol. 2018;42:359-66.

30. Eroglu Z, Zaretsky JM, Hu-Lieskovan S, Kim DW, Algazi A, Johnson DB, et al. High response rate to PD-1 blockade in desmoplastic melanomas. Nature 2018;553:3474-350.

31. Chen JY, Hruby G, Scolyer RA, Murali R, Hong A, Fitzgerald P, et al. Desmoplastic neurotropic melanoma: a clinicopathologic analysis of 128 cases. Cancer. 2008;113:2770-8.

32. Schatton T, Scolyer RA, Thompson JF, Mihm MC Jr. Tumorinfiltrating lymphocytes and their significance in melanoma prognosis. Methods Mol Biol. 2014;1102:287-324.

33. Aung PP, Nagarajan P, Prieto VG. Regression in primary cutaneous melanoma: etiopathogenesis and clinical significance. Lab Investig. 2017 (in press).

34. Gualano MR, Osella-Abate S, Scaioli G, Marra E, Bert F, Faure E, et al. Prognostic role of histological regression in primary cutaneous melanoma: a systematic review and meta-analysis. $\mathrm{Br} \mathrm{J}$ Dermatol. 2018;178:357-62.

35. van der Ploeg AP, van Akkooi AC, Haydu LE, Scolyer RA, Murali R, Verhoef C, et al. The prognostic significance of sentinel node tumour burden in melanoma patients: an international, multicenter study of 1539 sentinel node-positive melanoma patients. Eur J Cancer. 2014;50:111-20.

36. Murali R, Desilva C, Thompson JF, Scolyer RA. Non-sentinel node risk score (N-SNORE): a scoring system for accurately stratifying risk of non-sentinel node positivity in patients with cutaneous melanoma with positive sentinel lymph nodes. J Clin Oncol. 2010;28:4441-9.

37. Scolyer RA, Li LX, McCarthy SW, Shaw HM, Stretch JR, Sharma R, et al. Micromorphometric features of positive sentinel lymph nodes predict involvement of nonsentinel nodes in patients with melanoma. Am J Clin Pathol. 2004;122:532-9.

38. Gershenwald JE, Andtbacka RH, Prieto VG, Johnson MM, Diwan $\mathrm{AH}$, Lee JE, et al. Microscopic tumor burden in sentinel lymph nodes predicts synchronous nonsentinel lymph node involvement in patients with melanoma. J Clin Oncol 2008;26:4296-303.

39. Crookes TR, Scolyer RA, Lo S, Drummond M, Spillane AJ. Extranodal spread is associated with recurrence and poor survival in stage III cutaneous melanoma patients. Ann Surg Oncol. 2017;24:1378-85.

40. Gershenwald JE, Scolyer RA. Melanoma Staging: American Joint Committee on Cancer (AJCC) 8th Edition and Beyond. Ann Surg Oncol 2018;25:2105-10.

41. Haydu LE, Scolyer RA, Lo S, Quinn MJ, Saw RPM, Shannon KF, et al. Conditional survival: an assessment of the prognosis of patients at time points after initial diagnosis and treatment of locoregional melanoma metastasis. J Clin Oncol. 2017;35:1721-9.

42. Marchetti MA, Bartlett EK, Dusza SW, Bichakjian CK. Use of a prognostic gene expression profile test for T1 cutaneous melanoma: will it help or harm patients? J Am Acad Dermatol. 2019;80:e161-2.

43. Elder DE, M.D., Scolyer RA, Willemze R, editors. in WHO Classification of Skin Tumours. 4th ed. IARC: Lyon; 2018. 